Doi: 10.22478/ufpb.1983-1579.2019v12n3.46193

http://periodicos.ufpb.br/ojs2/index.php

\title{
OBSERVATÓRIO DO PARANÁ: o movimento curricular das licenciaturas em artes visuais
}

PARANÁ OBSERVATORY: visual art degree curricular movement

\author{
Consuelo Alcioni Borba Duarte Schlichta'
}

Resumo: Esse estudo sobre o movimento curricular das licenciaturas em Artes Visuais tem origem nas discussões sobre a especificidade do conhecimento artístico no ensino de arte, a partir da pedagogia histórico-crítica (SAVIANI, 2013). Busca-se pensar a contribuição do ensino de arte frente à alienação, ao poder hostil e destrutivo com que se defronta o(a) professor(a) (MÉSZÁROS, 2006), problematizando: o currículo proposto na licenciatura em Artes Visuais, da Universidade Federal (PR), corresponde às demandas de qualificação exigidas de quem atua no ensino de arte nos níveis fundamental e médio? Há aderência entre conhecimentos artísticos específicos e pedagógicos oferecidos na licenciatura em Artes Visuais (UFPR), os currículos das Secretarias de Educação e os conteúdos abordados na Educação Básica? Buscou-se compreender quem é o professor de carne e osso, a partir da crítica a tendência de se situar a subjetividade "dentro" e o social e o cultural "fora" do sujeito (GONZALEZ REY, 2012). Constatou-se que essa tendência encontrou expressão num projeto mais prescritivo de formação e menos aderente a investigação dos recursos subjetivos do professor no enfrentamento das situações cotidianas em sala de aula, a exemplo da prática institucionalizada de um único professor trabalhando com todas as linguagens. Enfim, como ele destrincha os conhecimentos específicos da arte (o quê) e os pedagógicos (o como) e o que resulta dessa amálgama, tendo em vista as condições cada vez mais adversas nas quais está mergulhada a escola no contexto atual brasileiro?

Palavras-Chave: Currículo; Formação do professor de arte; Subjetividade; Conhecimento; Conhecimento artístico e pedagógico.
Abstract: The present study of visual art degree curricular movement originated from discussions on the artistic knowledge specificities in art teaching, according to critical-historical pedagogy (SAVIANI, 2003). The study focuses on the art teaching contribution in view of alienation and destructive and hostile power teachers face (MÉSZÁROS, 2006). Our study raises the following: Does the Visual Art degree curriculum proposed in Universidade Federal do Paraná - UFPR (Paraná Federal University) meet the required qualifications demanded from junior and high school art teachers? Is there harmony between specific and pedagogical artistic knowledge offered by the Visual Art degree (UFPR), the Education Department curriculum and the Junior Education contents? Our study sought to understand who is the "flesh and Blood" teacher by taking into consideration criticisms towards the trend of considering subjectivity "inside" and social and cultural contexts "out of" the individual (GONZALEZ REY, 2012). We found out that the aforementioned trend was expressed in a more descriptive academic degree project rather than in a project focusing on investigating the teacher subjective resources used to face day by day classroom situations, such as the institutionalized practice of having only one teacher working with all of art languages. At last, how the teacher disentangle specific art (what) and pedagogic (how) knowledge and what resulted from that amalgamation, seeing that school is sinking into increasingly adverse conditions in the present Brazilian context?

Key-words: curriculum; art teacher degree; subjectivity; knowledge; artistic and pedagogic knowledge.

\section{INTRODUÇÃO}

${ }^{1}$ Doutorado em História pela Universidade Federal do Paraná. Professora associada da Universidade Federal do Paraná. . E-mail: consuelo.ufpr@gmail.com. ORCID: http://orcid.org/0000-0002-6928-9274. 
OBSERVATÓRIO DO PARANÁ: o movimento curricular das licenciaturas em artes visuaisSCHLICHTA, C. A. B. D.

A alienação, segundo Mészáros (2006, p. 14), corporificada "numa força externa que confronta os indivíduos como um poder hostil e potencialmente destrutivo", também exacerba o processo de exclusão de direitos sociais, culturais e educativos, nesse sentido, indagamos: quais os efeitos do afastamento dos professores em relação às decisões referentes ao currículo escolar? Os debates sobre o currículo da formação reafirmam ou não o protagonismo do professor? Sujeitos diretamente envolvidos na mediação do conhecimento na relação cognitiva, no processo ensino-aprendizagem, os professores têm poder decisório sobre o quê e o como ensinar, participam das discussões relativas ao ensino-aprendizagem da arte? Há correspondência entre o currículo da licenciatura e às demandas de qualificação do professor que atua no ensino de arte nos níveis fundamental e médio? Os conhecimentos artísticos e pedagógicos oferecidos na licenciatura fornecem indicadores sobre a especificidade do conhecimento artístico em sua forma de saber escolar? Dialogam com os currículos das escolas e as diretrizes traçadas nos documentos oficiais?

Considerando o professor concreto, conforme Gonzáles Rey (2003), enquanto subjetividade individual e social e as condições históricas e sociais como partes estreitamente inter-relacionadas de um sistema multidimensional, e a tríade de relações entre: “o sujeito que conhece, o objetivo do conhecimento e o conhecimento como produto do processo cognitivo" (SCHAFF, 1987, p. 72), tentamos pensar como sua formação reverbera futuramente na formação de outrem? Quais os principais obstáculos?

\section{CONFIGURANDO-SE PROFESSOR E OS EFEITOS DA ALIENAÇÃO}

Recorrentemente fala-se da formação-atuação, recorrendo ao discurso marcadamente idealista que desvincula o professor da realidade social, política, educativa. Um problema bem colocado por Klein (2012, p. 8): “Ao meramente contrapormos subjetividade e objetividade como esferas excludentes, ou ficamos nos infecundos limites do materialismo vulgar, ou bem descambamos para um deletério idealismo".

A ideia de professor como sujeito passivo e receptivo, conforme materialismo vulgar ou sob o idealismo, como alguém que tudo pode, ajuda-nos a explicar o discurso que toma o professor ora como vítima ora como vilão responsabilizando-o pelo fracasso da educação escolar. É o caso de se pensar a formação do professor perguntando: é suficientemente sólida como enfrentar esses discursos? Pois, exigem dele uma atitude radical, que ele "vá até às raízes da questão, até seus fundamentos"; rigorosa, "segundo métodos determinados, colocando-se em questão as conclusões da sabedoria popular e as generalizações apressadas que a ciência pode ensejar"; por fim, visão de conjunto, "relacionando-se o aspecto em questão com os demais aspectos do contexto em que está inserido". (SAVIANI, 2009, p. 20-21).

Não se trata da defesa de uma área específica do conhecimento, mas defesa da reflexão filosófica como "uma atitude que o homem toma perante a realidade" (SAVIANI, 2009, p. 19). A filosofia é necessária porque os problemas que a realidade impõe desafiam permanentemente o professor. Certos termos, em razão do esgarçamento resultante do seu uso excessivo, requerem re-significação. Saviani assim procede com o termo problema, esclarecendo que ele "possui um sentido profundamente vital e altamente dramático para a existência humana, pois indica uma situação de impasse. Trata-se de uma necessidade que se impõe objetivamente e é assumida subjetivamente" (SAVIANI, 2009, p. 19).

Não está em questão as disciplinas como Filosofia da Educação, Fundamentos do Ensino da Arte, elas são fundamentais no exercício permanente de reflexão do professor sobre os dilemas que enfrenta; mas de respaldar uma formação do professor apoiada num corpus filosófico suficientemente sólido. Por exemplo, a partir da reflexão crítica sobre o discurso de que o fracasso escolar é resultante da "incompetência técnica" ou do "descompromisso político" do professor (KLEIN, 2008, p. 19), que esse argumento não se sustenta na prática.

O enfrentamento desse da prática de um único professor trabalhar as quatro linguagens, mesmo que formado especificamente em Artes Visuais, Dança, Música ou Teatro, salvo exceções, contraria esse 
ISSN 1983-1579

Doi: 10.22478/ufpb.1983-1579.2019v12n3.46193

http://periodicos.ufpb.br/ojs2/index.php

discurso. Em uma das idas, uma professora, preocupada com o acesso de seus alunos ao conhecimento das diferentes linguagens, perguntou: "Mas, se eu não dispuser todos estes conteúdos aos alunos, quem mostrará?" A pedagoga, por sua vez, indagada sobre o trabalho com as quatro linguagens, assim se pronunciou: "Esta escola é privilegiada, pois possui profissionais específicos em arte. Em outros lugares é o professor que 'sobra' que geralmente é o que vai dar as aulas de arte e ponto"

Embora saiba que a prática polivalente não é “um cabresto", pois não é obrigada a trabalhar todas as linguagens, tem uma preocupação real com seus alunos: o acesso aos conteúdos nucleares das quatro linguagens. Preocupa-se em dar conta da responsabilidade de que assumiu com seus alunos e famílias. Afinal, todos almejam o mesmo: um ensino de qualidade (KLEIN, 2000).

O acesso ao conhecimento e a defesa da produção artística e cultural são lutas travadas permanentemente; portanto, é fundamental compreender as determinações históricas e sociais, políticas e educativas que reiteram estereótipos calcados no idealismo, calcados numa imagem do professor que paira acima dos fatos, pois que ele tem naturalmente consciência crítica; ou conformados numa visão mecanicista ou materialista vulgar que concebe o sujeito como

(...) agente passivo, contemplativo e receptivo, cujo papel na relação cognitiva é o de registrar estímulos vindos do exterior, papel semelhante ao de um espelho (no caso das percepções visuais). As diferenças entre as imagens da realidade percebidas pelos diferentes sujeitos que conhecem reduzem-se às diferenças individuais ou genéricas do aparelho perceptivo. (SCHAFF, 1987, p. 73).

No idealismo, "a predominância, se não a exclusividade, volta ao sujeito que conhece, que apercebe o objeto de conhecimento como sua produção" (SCHAFF, 1987, p. 74). Esse autor, fundamentado nas teorias marxistas, evidencia os limites do modelo mecanicista ou materialista vulgar (a predominância do objeto) e do modelo idealista e ativista (predominância do sujeito) e propõe-se o princípio da interação.

Contrariamente ao modelo mecanicista do conhecimento para o qual o sujeito é um instrumento que registra passivamente o objeto, é atribuído aqui um papel ativo ao sujeito submetido por outro lado a diversos condicionamentos, em particular às determinações sociais, que introduzem no conhecimento uma visão da realidade socialmente transmitida. (SCHAFF, 1987, 74).

Nessa linha, concordando com Klein (2000), o sucesso de qualquer projeto político-educativo depende da inserção do professor nos problemas que dizem respeito à educação, mas depende também de que todos

(...) se reconheçam como sujeitos da mesma classe social, igualmente vitimados pelos mecanismos de exclusão inerentes ao sistema de organização social contemporâneo que são, em última análise, os verdadeiros responsáveis pelas limitações e dificuldades de cada um, e se aliem na luta pela conquista das melhorias que possam garantir a qualidade do ensino. (KLEIN, 2000, p. 21).

A prática de maneira mais ou menos consciente comprova que nem o professor é passivo diante de uma educação intocável, nem a sociedade e regida por uma ordem social superior e sagrada. Tanto o professor quanto a escola e seu projeto político-educativo "mantêm a sua existência objetiva e real, ao mesmo tempo que atuam um sobre o outro" (SCHAFF, 1987, p. 73).

O homem depende tanto do meio ambiente natural quanto do meio cultural e que ambos o condicionam, ele reage diante das situações problemáticas buscando transpor os obstáculos e 
OBSERVATÓRIO DO PARANÁ: o movimento curricular das licenciaturas em artes visuaisSCHLICHTA, C. A. B. D.

transformá-los, conforme seus objetivos (SAVIANI, 2009). Porém, tendo em vista uma compreensão imediata de "necessidade" como experiência individual, não se pense que o autor está subjetivando o sentido do problema e que cada cabeça uma sentença. Sem perder de vista a formação filosófica necessária argumentando em favor de uma atitude filosófica diante do problema: "Refletir é o ato de retomar, reconsiderar os dados disponíveis, revisar, vasculhar numa busca constante de significado. É examinar detidamente, prestar atenção, analisar com cuidado" (SAVIANI, 2009, p. 20).

Para Kosik (1976, p. 10), “a práxis utilitária imediata e o senso comum a ela correspondente colocam o homem em condições de orientar-se no mundo, de familiarizar-se com as coisas e manejá-las, mas não proporcionam a compreensão das coisas e da realidade". A práxis, conforme explicitado acima, constitui uma amálgama de relações mais ou menos alienadas e configuradas pelos homens e mulheres na própria experiência subjetiva e social.

Para Mészáros (2006), a alienação tem afetado profundamente a produção e o consumo, inclusive a produção artística e a cultural, os processos de mediação e ensino-aprendizagem da arte, rebaixando tanto o professor quanto sua atividade a simples peças em uma engrenagem aparentemente familiar. Para Mészáros (2006) a tradução de algumas palavras-chave como o termo alienação, nem sempre é suficientemente adequada, exigindo esforços inauditos para compreensão seus sentidos. Recorremos a síntese elaborada por esse autor, pois familiarizado com as teorias marxistas, sobre os quatro aspectos principais da alienação: “a) o homem está alienado da natureza; b) está alienado de si mesmo (da sua própria atividade); c) de seu 'ser genérico' (de seu ser como membro da espécie humana); c) o homem está alienado do homem (dos outros homens)". (MÉSZÁROS, 2006, 19-20).

Afastado de sua natureza humana, efeito da alienação, sem poder decisório sobre o porquê, o que, o como ensinar, o professor fica à mercê das relações de poder próprias da sociedade capitalista atual, facilmente se impondo a ele currículos escolares, particularmente no campo da arte. Arriscamos dizer que ele se torna instrumento da mediação do conhecimento na relação cognitiva, de conteúdos que não se relacionam entre si, sem conexão entre o todo e as partes, listados por especialistas em gabinetes, sem o devido cuidado em relação aos conceitos que pressupõem um conhecimento anterior. Por vezes, conteúdos que pouco contribuem para a compreensão das práticas sociais e das práticas artístico-culturais.

Lembramos que o estudo da alienação também não é simples preocupação conceitual, na verdade, a compreensão de seus efeitos pode e deve armar o professor na crítica aos pré-conceitos, filhos do senso comum, que parasitam e enfraquecem a autonomia dele e de seus pares, impedindo-o de se fortalecer filosoficamente, criticamente.

Frente a tais questões, impõe-se cuidadosa reflexão sobre a tarefa do professor na emancipação dos sentidos dos homens e mulheres; e como decorrência da primeira, na socialização da produção artístico-cultural. Tarefas complementares, uma pressupõe a outra: produção, distribuição e consumo de novos sentidos filosóficos e artísticos. A realização dessa tarefa impõe duas escolhas: dos conteúdos correspondentes à concepção de arte e objetivos e "de métodos adequados que irá impulsionar os conteúdos curriculares na direção dos objetivos propostos" (SAVIANI, 2009, p. 80).

\section{O CURRÍCULO NÃO É INTOCÁVEL NEM SAGRADO: COM A PALAVRA O PROFESSOR}

O termo movimento, destacado no título do trabalho, perpassa uma compreensão das ementas e dos programas das disciplinas em permanente mudança e superação de um currículo como uma grade intocável de matérias e restrito a uma listagem de habilidades ou competências.

Ao tratar do currículo do Ensino da Arte, no que tange ao conhecimento, exige esclarecimento sobre os traços que diferenciam arte e ciência, enquanto campos de conhecimento da realidade humano-social que não se duplicam nem rivalizam. 
ISSN 1983-1579

Doi: 10.22478/ufpb.1983-1579.2019v12n3.46193

http://periodicos.ufpb.br/ojs2/index.php

Quatro autores trazem significativa contribuição para o debate sobre a arte como forma de conhecimento: o primeiro é Lukács (1966), para quem a arte é tanto quanto a ciência formas de conhecimento. Sobre a distinção entre conhecimento artístico e científico, argumenta que a antropomorfização é a forma peculiar de conhecimento artístico da realidade; enquanto a ciência, ao contrário, orienta-se pela desantropomorfização da realidade.

O segundo autor, Vázquez (1978), também situa a arte como forma de conhecimento, dedicando-se à reflexão sobre as diferenças entre arte e ciência, entre a função cognoscitiva de uma e de outra. Para Vázquez (1978), o conhecimento proporcionado pela arte não se reduz a mera duplicação do que a ciência já nos dá.

Os objetos não humanos representados artisticamente não são pura e simplesmente objetos representados, mas aparecem em certa relação com o homem; ou seja, revelando-nos não o que são em si, mas o que são para o homem, isto é, humanizados. O objeto representado é portador de uma significação social, de um mundo humano. Portanto, ao refletir a realidade objetiva, o artista faz-nos penetrar na realidade humana. (VÁZQUEZ, 1978, p. 35).

Conforme esclarece, embora o homem nem sempre seja o objeto da representação artística, a vida humana é o objeto específico da arte.

Assim, pois, a arte como conhecimento da realidade pode nos revelar um pedaço do real, não em sua essência objetiva, tarefa específica da arte, mas em sua relação com a essência humana. Há ciências que se ocupam de árvores, que as classificam, que estudam sua morfologia e suas funções; mas onde está a ciência que se ocupa das árvores humanizadas? Pois bem; são precisamente estes objetos que interessam à arte. (VÁZQUEZ, 1978, p. 35)

Dedica-se também à reflexão sobre a arte como forma de criação e investiga os traços específicos da práxis criadora em contraposição à práxis reiterativa, destacando os seguintes aspectos próprios da práxis criadora: "unidade entre o interior e o exterior, entre o subjetivo e o objetivo, no processo prático; imprevisibilidade do processo e de seu resultado; e unicidade e irrepetibilidade do produto" (VÁZQUEZ, 1977, p. 279).

Pareyson (1984), nosso terceiro autor referência, investiga as três definições tradicionais da arte: fazer, conhecer e exprimir. Sua concepção de conhecimento artístico relaciona-se ao aspecto visível, cognoscível, contemplativo da arte e citando Leonardo da Vinci, argumenta que certos artistas podem fazer ciência por meio da arte como forma de conhecimento. Porém, longe de reduzi-la ao seu aspecto cognoscitivo, enfatiza a arte como um modo particular de visão sobre a realidade, entendendo que esses olhares são sobretudo construtivos; e dá destaque à concepção de arte como produção de objetos radicalmente novos. Enfatiza o aspecto criador da arte, contudo, observa:

O fato é que a arte não é somente executar, produzir, realizar e o simples "fazer" não basta para definir sua essência. A arte é também invenção. Ela não é execução de qualquer coisa já ideada, realização deum projeto, produção segundo regras dadas ou predispostas. Ela é um tal fazer que, enquanto faz, inventa o por fazer e o modo de fazer. (PAREYSON, 1984, p. 33).

Por último, destacamos Canclini (1984), contrário às concepções atemporais, metafísicas que pretendem definir o "o que é $a$ arte", ele problematiza "o que faz de um objeto uma obra de arte e permite diferenciá-lo dos demais objetos?” (CANCLINI, 1984, p. 10). Assim, para ele, o estético não é 
OBSERVATÓRIO DO PARANÁ: o movimento curricular das licenciaturas em artes visuaisSCHLICHTA, C. A. B. D.

(...) nem uma essência de certos objetos, nem uma disposição estável do que se chamou 'a natureza humana. É um modo de relação dos homens com os objetos, cujas características variam segundo as culturas, os modos de produção e as classes sociais (CANCLINI, 1984, p. 11).

Consequentemente, critica o pretenso descolamento das obras de arte das suas condições de produção, pois, quem tem o poder econômico também impõe, conforme lógica do capitalismo, os padrões estéticos que chancelam o que é Cultura e Arte e o que ingressa nos panteões do Sistema de Arte e da História da Arte.

Os quatro autores, embora por caminhos diferentes explicitam o aspecto ativo do conhecimento na construção de novos olhares; como fator determinante na emancipação dos sentidos estéticos, em particular da sensibilidade, que requer sentidos estéticos. Vázquez (1978) argumenta, somente um olho que conhece, reconhece e aprecia as qualidades próprias de um objeto (cor, peso, proporção etc.), é capaz de captar os sentidos que os objetos artísticos adquirem, dotá-los de novos sentidos, ou seja, qualidades que não pertenciam naturalmente a eles e que denominamos qualidades estéticas. Por exemplo, os desenhos das estrias que se alternavam simetricamente em um objeto ou das ranhuras nas paredes das cavernas exigiram certa autonomia de nossos antepassados.

Uma formação imbricada na conversão dos conhecimentos específicos da arte e dos conteúdos do ensino-aprendizagem da arte impõe condições, a exemplo da definição de quais conteúdos ensinar e como abordá-los? Por extensão, que se leve em conta o vínculo formação atuação do professor, o que e o como fazer de modo a garantir à familiarização do aluno com a produção artística? Arte:

No que se refere à emancipação dos sentidos humanos entendemos que é objetivo da Educação em

Criar necessidades e prazeres especificamente humanos, tais como: acuidade perceptiva e a agudeza de sensibilidade, o exercício da capacidade de reflexão, de interpretação e de crítica, entre outros, pois que a arte é criação-produto específico do homem e só à sua humanização deve se destinar. (PEIXOTO, 2003, p. 47-48).

Mas que ações são necessárias para se assegurar a emancipação dos sentidos? Como garantia do primeiro objetivo, é fundamental proporcionar "condições concretas de acesso às obras, em quantidade (extensão) e em qualidade (intensidade) compatíveis com um padrão elevado de arte ao maior número possível de pessoas". (PEIXOTO, 2003, p. 47). Em terceiro, empreender uma crítica ao "consumo massificado e passivo", resultante da percepção ingênua da arte em direção da percepção estética como "apropriação-fruição das obras que promova a consciência e permita o desenvolvimento da autoconsciência". Por fim, possibilitar "ao fruidor atento uma nova consciência" e um "adensamento da autoconsciência", que estão, "dialeticamente imbricadas e dizem respeito, numa dada sociedade, à superação do senso comum” (PEIXOTO, 2003, p. 47-48).

Nesse contexto, um dos seus mais difíceis enfrentamentos diz respeito a exigência de um único professor trabalhar as quatro linguagens, mesmo que formado especificamente em Artes Visuais, Dança, Música ou Teatro, salvo exceções. As respostas da pedagoga e da professora de uma das escolas em relação ao trabalho com as quatro linguagens são prova das urgências que se move e ensina o professor. A pedagoga assim se pronunciou: "Esta escola é privilegiada, pois possui profissionais específicos em arte. Em outros lugares é o professor que 'sobra' que geralmente é o que vai dar as aulas de arte e ponto." A professora, por sua vez, justificou: "As linguagens não são um cabresto; mas, se eu não dispuser todos estes conteúdos aos alunos, quem mostrará?” 
ISSN 1983-1579

Doi: 10.22478/ufpb.1983-1579.2019v12n3.46193

http://periodicos.ufpb.br/ojs2/index.php

A distância entre a escola e a universidade citada é compreendida como afastamento em relação a indefinição que paira: formação específica ou atuação nas quatro linguagens? Argumentam que eles não têm suficiente conhecimento das quatro linguagens e preocupam-se com "quem vai sofrer as consequências"? Dizem lamentar pelos alunos que só tem na escola uma via de acesso à arte. Por isso a preocupação da professora com as divisões pouco explicadas que acabam minando as relações, por exemplo: de um lado, professor regente (responsável pela turma e demais áreas de conhecimento); de outro, o "especialista", numa referência ao professor do Ensino de Arte ou da Educação Física, que trabalham apenas uma disciplina. Embora reconheçam que soluções de toda ordem são debatidas pela categoria e que alguns avanços já foram incorporados na forma da lei. Por exemplo, a Lei de Diretrizes e Bases da Educação Nacional (LDB) n 5.692/71, que tornou obrigatória a Educação Artística entendida à época como atividade e não como disciplina. Eles têm ideia de que a obrigatoriedade representou um avanço, porém vivem na pele, muda-se a forma não conteúdo, pois a prática de um único professor trabalhar as quatro linguagens dos anos de 1970 chega ao século XXI (ALVARENGA e SCHLICHTA, 2016). Abrigada sob a nova nomenclatura: Ensino da Arte, por vezes adota denominações mais contemporâneas. As falas dos professores, a sede de conhecimentos nas linguagens só comparável aos esforços dedicados na busca por resposta.

Vicejam inúmeras propostas de reordenação curricular. A fala de uma aluna egressa do Curso de Licenciatura em Artes Visuais, professora no Ensino Médio, elucida os esforços feitos:

A gente tem muitos problemas, porque um é formado em Música, outro formado em Teatro, outro em Artes Visuais, e até em Educação Artística. Um quer trabalhar as quatro linguagens, conforme a formação; o outro quer trabalhar só música, o outro quer trabalhar só teatro. Em alguns momentos a gente tenta se basear nas diretrizes, principalmente aqui do Paraná, para organizar esse conteúdo. Mas, em geral, fica de acordo com a sua linguagem; em alguns momentos os professores de música inventam de dar aula de artes visuais, por causa do barulho, não tinha sala, espaço adequado para ensinar música. Então para eles é mais fácil trabalhar as artes visuais. Assim como eu ensino um pouco de música, eles ensinam artes visuais. E teatro a mesma coisa. Então, na hora atividade e no período que os professores se reúnem nos intervalos das aulas, a gente conversa, troca ideia, referências, material para organizar as aulas. A gente consegue fazer desse jeito. Mas não sei se é o ideal. Você teria que ficar trabalhando o que você não estudou.

Uma professora destacou duas saídas recorrentes no enfrentamento desse problema: aceitar e trabalhar as quatro linguagens; ou interpretar a orientação "entendendo que as diretrizes e PCNs são uma verdade absoluta", as falas evidenciam práticas assimiladas desde os anos de 1970, mas também novos olhares.

Aceitar trabalhar as quatro linguagens de forma articulada o um bimestre trabalhar artes visuais; outro, música, depois, teatro. A orientação é que 'você tem que trabalhar todas as linguagens, tem que estar pensando isso, esse aqui é o conteúdo programático, então você tem que se basear nisso para fazer o teu planejamento'. Então, em alguns momentos eu aceitava isso, mas não totalmente; eu trabalhava mais artes visuais. Eu tentei fazer isso mesmo não tendo a formação, o que eu achava totalmente errado; por isso, estudando, lendo, entendendo que as diretrizes e PCNs não são uma verdade absoluta que você tem que seguir, hoje eu trabalho com as artes visuais, minha área. E, buscando relações com as outras 
OBSERVATÓRIO DO PARANÁ: o movimento curricular das licenciaturas em artes visuaisSCHLICHTA, C. A. B. D.

áreas, principalmente agora na contemporaneidade, não dá para ignorar a relação que a gente vê na performance, na instalação, vídeo.

Observa-se que a imagem do professor de arte avesso à teoria cai por terra por terra pois todos têm uma concepção de mais ou menos elaborada a partir noção de arte linguagem. A imagem tratada como um texto visual, passível de leitura de seus códigos de composição e elementos formais rapidamente foi absorvida.

Como destacamos anteriormente, a carência do professor em relação ao como ensinar é comprovada pela rápida absorção da leitura e releitura de imagens, extraída da Abordagem Triangular, de Ana Mae Barbosa (1991). Com todos os acertos e equívocos, essa prática dominante desde os anos de 1980 tem um grande mérito: trazer para o centro das aulas de arte e imagem oportunizando os debates sobre o objeto de estudo do ensino da arte nos anos subsequentes.

O relato de uma professora do Ensino Médio comprova a importância da leitura da imagem e evidencia que os professores e pesquisadores a partir de então debruçam-se sobre o que é esse objeto imagem.

Eu fiz uma disciplina que era leitura de imagem. Na graduação tinha uma disciplina optativa de leitura de imagem, mas eu não quis fazer, ou o horário não bateu com meu trabalho. Mas eu fiz no Mestrado, a professora, que trabalhava com a Semiótica, abordou a questão: o que é imagem? E a dificuldade de se pensar e de se definir o que é imagem é grande. Muitas vezes o uso equivocado que se faz, generalizando-se que tudo é imagem. Eu não vou te dar uma definição, porque eu não sei dizer o que imagem é. Penso que imagem está relacionada à visualidade.

Resulta daí um debate sobre o objeto específico do ensino da arte, no sentido de aprofundar a compreensão do conceito de representação, com ênfase nos estudos da produção artística e cultural, do ângulo da sua transparência (o que é dado a ver de imediato?) e da sua opacidade (que conhecimentos mediam o encontro entre o leitor e o autor, de modo que o primeiro compreenda o segundo no tempo e espaço histórico da sua produção).

A centralidade da imagem ressalta um objeto de estudo no âmbito do ensino da arte, mas exige também um conhecimento específico sobre a coisa que se quer conhecer e um conhecimento sobre o como fazer para que os alunos compreendam os sentidos desse objeto. Em suma, entendemos o ensino-aprendizagem da arte como um processo teórica e metodologicamente balizado por conhecimentos específicos da arte e de seu ensino-aprendizagem com vistas a superação do desconhecimento da coisa para seu conhecimento, ou seja, o que dá a esse objeto estatuto de arte?

É digno de nota a atenção e o esforço dos professores para extrair do campo denominado arte, independentemente das pesquisas e contextualizações da singularidade do objeto de trabalho, que é central no Ensino da Arte, comprovando que a necessidade de dar conta de um problema impulsiona a busca de respostas. Nesse caso, a Cultura Visual tem sido mencionada sob a justificativa de que a cultura amplia o leque de objetos que pertencem ao campo visual, incluindo-se a imagem, a visualidade, a estética do cotidiano etc. Destacam-se os estudos organizados por Martins e Tourinho (2009) sobre o papel da Cultura Visual na formação em Artes Visuais.

O termo visualidade parece denominar um conjunto de objetos, por excelência do campo visual. Uma professora assim justifica a visualidade no Projeto Político-Pedagógico de sua escola:

O PPP vai te dando direcionamentos, então, independente do que você ache importante, tem que pensar um pouco nisso, daí colocar tua experiência de vida e docente Depois, tem os Parâmetros Curriculares Nacionais e as Diretrizes 
ISSN 1983-1579

Doi: 10.22478/ufpb.1983-1579.2019v12n3.46193

http://periodicos.ufpb.br/ojs2/index.php

Curriculares próprias do Estado, tem uma orientação geral na área da visualidade para trabalhar com História da Arte, em alguns momentos de maneira linear, pensando desde a Pré-história até Arte Contemporânea, mas se quiser trabalhar profundamente todos esses pontos, nunca chega em Arte Contemporânea, então melhor trabalhar de modo não linear fazendo links com o que ocorreu na contemporaneidade e em outros movimentos artísticos e até com as técnicas.

O artístico, a cultura, a imagem encaixam-se mais ou menos na denominação visualidade, entretanto, ao abordar como abordam qualquer objeto da visualidade é recorrente a prática da leitura de imagens, como esclarece uma professora formada na Licenciatura em Artes Visuais (UFPR).

Os professores formadores influenciam muito os alunos da graduação e isso vai virando uma bola de neve, vai se reproduzindo. Mas é preciso continuar pesquisando novas formas, inclusive de leitura de imagem. Eu estive num evento em que a professora trabalhou cinco modos diferentes de fazer leitura de imagem. $\mathrm{E}$ eu falei: "nossa, se eu tivesse tido isso na graduação, um professor que mostrasse, oh, existem essas formas e atividades práticas de como fazer análise da imagem, em grupo ou individualmente. Clareia a mente, é mais uma possibilidade.

Enfim, o que assombra o professor é o desconhecimento de seu campo de atuação, por isso, ao mesmo tempo que ele parece marcar passo no mesmo lugar, pois teima em externar os problemas persistentes, ele faz avançar o estado da arte. A compreensão de que "o capitalismo transforma tudo em mercadoria, inclusive o próprio conhecimento e os mecanismos de acesso a ele", e ao mesmo tempo e na mesma proporção que produz muita riqueza produz muita pobreza (KLEIN, 2000, p. 18). A compreensão da lógica de produção, distribuição, consumo do conhecimento no capitalismo ajuda-os a pensar que o enfrentamento dos impasses no trabalho docente exige respostas do professor, daí rendendo frutos. Porém, desconhecendo os mecanismos de produção, distribuição e consumo dos bens simbólicos, expropriado da vital atitude filosófica, artística e educativa sobre seu trabalho, o professor não usufrui dos frutos do seu trabalho.

A expressão "treino é treino" ou a representação de artista como alguém "que nunca se viu de roupa limpinha" são usadas com certo cuidado, em razão das críticas, mas são reveladoras das inseguranças, muitas vezes tratadas sem o devido cuidado em explicitar os fundamentos do que constitui a técnica vazia ou como uma receita.

No caso da expressão "treino é treino", a professora referia-se "à necessidade de treino na fase de transição da letra de forma para a cursiva (alunos entre 7 e 8 anos), inclusive na escrita do cabeçalho do caderno de artes".

No outro caso, a professora valeu-se de uma noção de "artista", como um homem com as "mãos na massa", de alguém com as roupas sujas de tinta, diante da impossibilidade de deixar sua turma sair da sala para lavar as mãos após uma atividade com tinta azul, no mesmo horário do recreio dos maiores. 0 desconhecimento dos sentidos dos termos na sua origem revela-se nos pré-conceitos que se usa para descrever uma visão de artista. É exemplar a noção de artista como homem da prática, fartamente analisada por Vázquez (1977) para explicar o que distingue prática de práxis. Esse autor, como já dissemos, argumenta que unidade entre objetividade e subjetividade, entre interior e exterior resulta numa reflexão sobre a ação, que é ao mesmo uma ação reflexiva.

Mas, para não cair na dicotomia subjetividade "dentro" e objetividade “fora”, retomamos González Rey (2017), no que se refere as configurações subjetivas, 
que integram a subjetividade social e a individual (...), cujos sentidos subjetivos invariavelmente expressam a subjetividade social e são parte dela. Os sentidos subjetivos gerando pelas configurações subjetivas individuais sempre aparecem dentro de redes relacionais atravessadas por todas produções subjetivas da sociedade que estão além de um espaço social concreto (GONZÁLEZ REY, 2017, p. 44).

O princípio da interação, conforme materialismo histórico dialético, rege o sentido do termo unidade e é revelador da ideia de processo criador resultante da amálgama, das interações, das configurações entre "um tal fazer que, enquanto faz, inventa o por fazer e o modo de fazer" (PAREYSON, 1984, p. 33).

A partir dessas premissas podemos, agora, extrair sentidos do argumento que a professora usou para dar conta de um problema prático: a grande diferença de idade entre as crianças maiores e maiores e a preocupação da escola em prevenir quaisquer atritos devido ao significativo número de crianças no recreio, por isso sua organização em dois horários. Tentando lidar com o incômodo das mãos "sujas" de tinta das crianças e da impossibilidade de saírem, argumentou: "Como mão de artista! Afinal, onde já se viu algum artista trabalhar com tinta e ficar todo limpinho?"

Valeu-se de seu repertório de saberes traz à baila a concepção de arte que acentua seu aspecto fabril, manual (PAREYSON, 1984), amplamente reiterada, lança mão também do estereótipo de artista como alguém com suas mãos e roupas cobertas de tinta, em meio a uma profusão de potes de tinta, pincéis e telas e objetos espalhados pelo ateliê. Essa imagem de ateliê do artista amplamente disseminada tem origem no acesso às obras de arte reproduzidas em livros didáticos, da História da Arte etc. Cai por terra também a concepção idealista de contemplação, de um lado, das obras de arte como uma disposição do sujeito para acolher a "revelação" dos seus sentidos; de outro, de criação como resultado "da genialidade excepcional de seus criadores" (CANCLINI, 1984, p. 10).

No contexto de trabalho com as imagens também não se sustenta a sua leitura mediante descrição do que que se vê. A leitura da imagem do ateliê do artista, por exemplo, naquilo que transparece, no que é dado a ver, se não problematizar em seus sentidos históricos, estéticos, políticos, só acentua os estereótipos e pré-conceito sobre o artista e do lugar de trabalho. Há inúmeras fontes, um manancial de imagens que, no seu título da obra, fazem referência ao atelier, à oficina e ao estúdio etc. Sua compreensão, enfim, pressupõe uma percepção filosófico-estética de seus sentidos, por isso, concordando com Ochoa (1986, p. 14 a 16),

ver é convencional, cultural, construído, e os modos de ver resultam do social, são práticas sociais. [...] Portanto, se a leitura de imagens ou de mensagens visuais é algo que requer um aprendizado; se a visão humana tem uma história que se desenrola em relação com as formas de representação, estas sempre culturais; se a compreensão do visual se baseia em convenções históricas e socialmente variáveis, teremos então que propor o problema da existência de códigos nas mensagens icônicas.

Alguns professores ao falar sobre a formação destacam a necessária articulação teoria-prática. Um deles argumentou:

$\mathrm{Na}$ graduação senti falta de pensar as disciplinas pedagógicas associadas às disciplinas específicas, na formação inicial deveria se pensar de modo conjunto as disciplinas pedagógicas e específicas, a parte conceitual do conteúdo ao como ensinar na prática, como o professor pode fazer essa transposição do que ele está vendo na graduação com o como ele pode trabalhar isso na prática. 
ISSN 1983-1579

Doi: 10.22478/ufpb.1983-1579.2019v12n3.46193

http://periodicos.ufpb.br/ojs2/index.php

Enfim, e evidente que o professor "tem milhões de coisas para fazer", como comprova a significativa quantidade de atividades que descreve: "aula para planejar, livro para preencher, pesquisar na Internet e baixar imagens, vídeos, para depois passar para os alunos". Há uma preocupação evidente com o acesso ao conhecimento, como comprova um pensamento comum: "Senão os alunos ficam com um conhecimento muito reduzido". As urgências são tantas que se passa a viver "sem tempo de ir atrás do PPP", muitas vezes, "uma coisa que está só no papel”, diz uma professora.

Até porque o que todos falam é que uma coisa é o que está no papel, isso infelizmente acontece, outra o cada um trabalha dentro da sala de aula, como quer e não tem essa conversa, esse tempo de troca, de conversa não tem. E isso que a escola que eu trabalho tem Hora Atividade concentrada, as disciplinas têm um dia para hora atividade do professor. Um tempo para você pode trocar ideias, planejar com colegas e tal.

Enfim, as políticas educacionais permanecem as palavras que tecem elogios à Educação nos documentos e leis ou se dá condições materiais de sustentação das palavras, que substanciem o compromisso político do Estado com um projeto de Educação, que respalde uma formação nos moldes elevados que constitui a condição humana.

\section{CONSIDERAÇÕES FINAIS}

A partir das falas e dos aprendizados da formação inicial e continuada resultantes da amálgama teoria-prática, tentamos compreender quem é o professor concreto que, mesmo trabalhando em condições precárias e adversas, ele não apenas transpõe também propõe novas formas de sistematização e abordagens dos conteúdos. Acima de tudo, preocupa-se com as consequências do desconhecimento.

Por isso, nosso intento foi alertar os professores formadores em relação aos vazios na abordagem teórico-metodológica correspondente aos conhecimentos artísticos e pedagógicos inter-relacionados às formas adequadas ao ensino-aprendizagem da arte; as dúvidas do professor em relação aos conteúdos artísticos, tendo em vista sua articulação sociocultural e lógico-psicológico do aluno; e a interdependência formação e atuação na Educação em Arte.

Evidentemente não é o caso de esperarmos o professor por si só superação de seus desconhecimentos sobre o papel da arte na emancipação humana. É tarefa do professor formador pensar e propor, indicar caminho na direção da crítica, rompimento e superação da hipertrofia do preparo pedagógico-didático em detrimento do preparo artístico-educativo.

Diante dessas exigências, destacamos dois questionamentos finais, que seguem no horizonte das pesquisas realizadas pelo Observatório da Formação de Professores de Arte: em primeiro lugar, partindo do materialismo histórico-dialético que concepção de desenho curricular de formação de professor tem sido absorvida, quais seus avanços ou limites? Como os professores formadores lidam com a contradição de atuarem numa licenciatura que forma o professor numa linguagem específica, aprovada pelo Estado, testada, que nega recursos para as políticas educacionais inviabilizando a superação da prática de um único professor trabalhar por quadro, sem reconhecimento e culpabilizado pela crise social que reverbera na escola, que faz ouvidos moucos às vozes da escola?

De acordo com a concepção histórico-critica almeja-se uma formação claramente voltada aos interesses daqueles que são à maioria escola pública: as classes populares. E que amplie o acesso, e a devida compreensão dos sentidos da produção artística e cultural, de modo que os alunos tenham fome de arte, tratando-se como necessidade vital. De uma direção na perspectiva da superação dos limites das necessidades básicas, para que professores e alunos ampliem sua necessidade, enriquecendo-se de arte. 
OBSERVATÓRIO DO PARANÁ: o movimento curricular das licenciaturas em artes visuaisSCHLICHTA, C. A. B. D.

Trata-se de ser professor de arte, aquele que lida com a dimensão artística do currículo escolar, que se ocupa da arte e a cultura como forma de ser livre.

\section{REFERÊNCIAS}

BARBOSA, Ana Mae. A imagem no ensino da arte: anos oitenta e novos tempos. São Paulo. Perspectiva; Porto Alegre: Fundação IOCHPE, 1991.

BRASIL. Parâmetros Curriculares Nacionais: arte. v. 6. Ministério da Educação. Secretaria da Educação Fundamental. 3 ed. Brasília: A Secretaria, 2001.

CANCLINI, Nestor G. A socialização da arte: teoria e prática na América Latina. 2 ed. São Paulo: Cultrix, 1984.

GONZÁLES REY, Fernando Luis. O social na psicologia e a psicología social: a emergência do sujeito. Petrópolis, RJ: Vozes, 2012.

. Sujeito e subjetividade. São Paulo: Thomson, 2003.

. Pesquisa qualitativa em psicologia: caminhos e desafios. Tradução de: SILVA, M. A. F. São Paulo: Thomson Pioneira Learning, 2002. Título original: Investigacíon cualitativa em psicologia.

KLEIN, Ligia Regina. Apresentação. In: CHAGAS, E. F.; RECH, H. L.; VASCONCELOS, R. e MATA, W. da (org.). Subjetividade e Educação. Fortaleza: Edições UFC, 2012. p. 7-18.

KLEIN, Ligia Regina. Alfabetização: quem tem medo de ensinar? 5. ed. São Paulo: Cortês; Campo Grande: Editora da Universidade Federal de Mato Grosso do Sul, 2008.

- Proposta Político-Pedagógica para o Ensino Fundamental. Cadernos da Escola Guaicuru. Secretaria de Estado de Educação. Núcleo de Ensino. Mato Grosso, 2000.

KOSIK, Kosik. Dialética do concreto. 2. ed. Rio de Janeiro: Paz e Terra, 1976.

LUKÁCS, György. Estetica: la peculiaridad de lo estetico. Cuestiones preliminares y de principio. $2^{\mathrm{a}}$ ed. Barcelona: Grijalbo, vol. 1. 1966.

MARTINS, Raimundo; TOURINHO, Irene. Educação na Cultura Visual: narrativas de ensino e pesquisa. Santa Maria: Ed. da UFSM, 2009.

MÉSZÁROS, István. A teoria da alienação em Marx. Tradução de: TAVARES, I. São Paulo: Boitempo, 2006. Título original: Marx's theory of alienation.

OCHOA, César González. Imagen y Sentido: Elementos para uma semiotica de los mensajes visuales. México: Universidad Nacional Autónoma de México, 1986.

PAREYSON, Luigi. Os problemas da estética. 1.ed. Tradução de: GARCEZ, M. H. N. São Paulo: Martins Fontes, 1984. Título original: I problemi dell'estetica.

PEIXOTO, Maria Inês Hamann. Arte e grande público: a distância a ser extinta. Campinas: Autores Associados, 2003.

SAVIANI, Dermeval. Pedagogia histórico-crítica: primeiras aproximações. 11. ed. Campinas, SP: Autores Associados, 2013.

. Educação: Do senso comum à consciência filosófica. 18. ed. Campinas, SP: Autores Associados, 2009.

SAVIANI, Nereide. Saber escolar, currículo e didática: problemas da unidade/método no processo pedagógico. 4. ed. Campinas, SP: Autores Associados, 2003. 
ISSN 1983-1579

Doi: 10.22478/ufpb.1983-1579.2019v12n3.46193

http://periodicos.ufpb.br/ojs2/index.php

SCHAFF, Adam. História e verdade. 4. ed. São Paulo: Martins Fontes, 1987.

SCHLICHTA, C. A. B. D.; ALVARENGA, V. M. O currículo das licenciaturas em Artes Visuais no Paraná: do proposto na lei à formação e atuação do professor. In: BUJÁN, F.; FRADE, I. N.; FONSECA DA SILVA, M. C. da R \& COHAS, M. G. de la E. (Org.). Investigación y Formación en Artes: Miradas desde América Latina. Valparaíso; Florianópolis: UDESC; Universidade de Playa Ancha; Selo Editorial Puntángeles, 2018.

VÁZQUEZ, Adolfo Sanchez. As ideias estéticas de Marx. Tradução de: COUTINHO, C. N. 2. ed. Rio de Janeiro: Paz e Terra, 1978. Título original: Las ideas esteticas de Marx.

. Filosofia da praxis. 2 ed. Rio de Janeiro: Paz e Terra, 1977.

SECRETARIA DE ESTADO DA EDUCAÇÃO. Tradução de: CARDOSO, L. F. Currículo básico para a escola pública do estado do Paraná. Curitiba/ PR: Imprensa Oficial, 1990. Título original: Filosofia da praxis.

SECRETARIA DE ESTADO DA EDUCAÇÃO DO PARANÁ. Diretrizes curriculares da educação básica: Arte. Departamento de Educação Básica. Curitiba/ PR: Imprensa Oficial, 2008.

SECRETARIA MUNICIPAL DA EDUCAÇÃO. Currículo Básico: uma contribuição para a escola pública brasileira. Curitiba/ PR: Imprensa Oficial, 1898.

SECRETARIA MUNICIPAL DA EDUCAÇÃO. Currículo Básico: compromisso permanente para a melhoria da qualidade do ensino na escola pública. Impressão Coygraf: Curitiba, 1991. 
OBSERVATÓRIO DO PARANÁ: o movimento curricular das licenciaturas em artes visuaisSCHLICHTA, C. A. B. D.

Recebido em: 30/05/2019

Aceito em: 14/08/2019

Publicado em: 03/10/2019

Rev. Espaço do Currículo (online), João Pessoa, v.12, n.2, p. 335-347, ser/dez. 2019. 